\title{
Class D audio amplifier with 4th order output filter and self-oscillating full-state hysteresis based feedback driving capacitive transducers
}

Nielsen, Dennis; Knott, Arnold; Andersen, Michael A. E.

Published in:

Proceedings of EPE'14-ECCE

Link to article, DOI:

10.1109/EPE.2014.6910924

Publication date:

2014

Document Version

Peer reviewed version

Link back to DTU Orbit

Citation (APA):

Nielsen, D., Knott, A., \& Andersen, M. A. E. (2014). Class D audio amplifier with 4th order output filter and selfoscillating full-state hysteresis based feedback driving capacitive transducers. In Proceedings of EPE'14-ECCE IEEE. https://doi.org/10.1109/EPE.2014.6910924

\section{General rights}

Copyright and moral rights for the publications made accessible in the public portal are retained by the authors and/or other copyright owners and it is a condition of accessing publications that users recognise and abide by the legal requirements associated with these rights.

- Users may download and print one copy of any publication from the public portal for the purpose of private study or research.

- You may not further distribute the material or use it for any profit-making activity or commercial gain

- You may freely distribute the URL identifying the publication in the public portal 


\title{
Class D audio amplifier with 4th order output filter and self-oscillating full-state hysteresis based feedback driving capacitive transducers
}

\author{
Dennis Nielsen, Arnold Knott \& Michael A. E. Andersen \\ Technical University of Denmark \\ Oersteds Plads, Building 349 \\ Dk-2800 Kgs. Lyngby, Denmark \\ Phone: +4545253490 \\ Fax: +4545880117 \\ Email: deni@elektro.dtu.dk \\ URL: http://www.elektro.dtu.dk
}

\section{Keywords}

Sliding mode control, High voltage power converters, Drive, Active damping, Amplifiers

\begin{abstract}
A practical solution is presented for the design of a non-isolated high voltage DC/AC power converter. The converter is intended to be used as a class D audio amplifier for a Dielectric Electro Active Polymer (DEAP) transducer. A simple and effective hysteretic control scheme for the converter (buck with fourthorder output filter) is developed and analyzed. The proposed design is verified experimentally by a 125 VAR prototype amplifier, capable of delivering a peak output voltage of $240 \mathrm{~V}$ within the frequency range of $100 \mathrm{~Hz}-3.5 \mathrm{kHz}$. A peak efficiency of $87 \%$ is reported.
\end{abstract}

\section{Introduction:}

Sound reproduction systems are commonly build around class D audio amplifiers due to their superior cost, size and efficiency compared to their linear counterparts $[1,2,3,4,5]$. While these audio systems are dominating the market of sound reproduction, they still suffer from the poor efficiency imposed by the electrodynamic transducer. An alternative to the electrodynamic transducer is the capacitive transducer. Capacitive transducers are most known from their usage in electrostatic loudspeakers, however Dielectric Electro Active Polymers (DEAP) can also be used to form a capacitive transducer $[6,7,8]$. With the goal of creating smaller, cheaper and more efficient audio systems it is proposed to use a class D amplifier as driver of the capacitive transducer $[9,10]$. Class D amplifiers driving a capacitive transducer without the use of audio or high frequency linked transformers, is an area of research with little to no publications. This paper addresses the issue of limited frequency response and high series resistance of capacitive transducers. The focus of the paper is placed upon Dielectric Electro Active Polymer (DEAP) transducers, however the concept can easily be extended to other capacitive transducers like piezoelectric ones.

A push DEAP transducer is shown in figure 1, while the measured impedance of the transducer is presented in figure 2. It is observed from figure 2, that the transducer cannot be expected to act as a capacitor for frequencies above $100 \mathrm{kHz}$. This limits the switching frequency significantly, if the output filter is constructed entirely by an inductor and the DEAP. Film or ceramic capacitors could be placed in parallel with the DEAP transducer. This will improve the frequency response. However it will also increase the reactive output power of the amplifier, because the capacitive load is increased. Another concern of the DEAP transducer is the series resistance. Older versions of the DEAP material [6] exhibited series resistance up to $50 \Omega$, while the present versions are specified within the region of $1-10 \Omega$. The connection between the DEAP transducer and the surrounding electronics is even more complicated than that of the film capacitor. DEAP transducers are constructed by printing compliant electrodes on a silicone membrane. The contact is performed on a surface exposed to significant mechanical stress. 


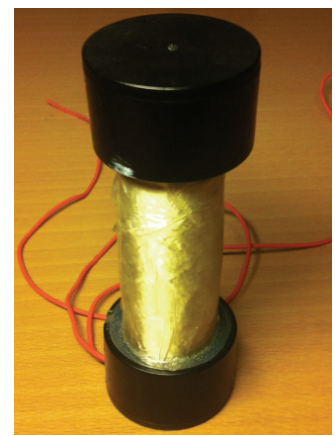

Figure 1: DEAP push transducer.

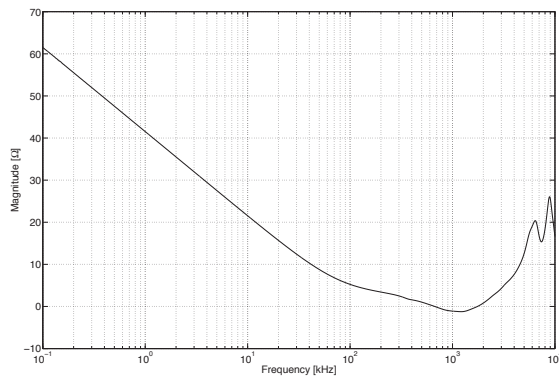

(a) Magnitude.

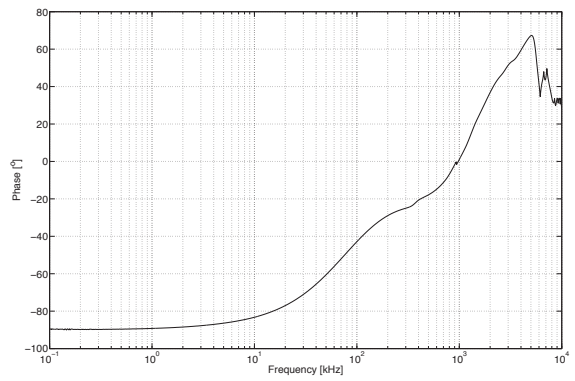

(b) Phase.

Figure 2: Measured impedance.

\section{Theory}

Due to the high series resistance of the DEAP transducer, the magnitude of the ripple current becomes a concern. Conduction losses will dominate, if the ripple current becomes to high. This is both a problem in terms of efficiency, but also because of the reduced lifetime of the contact interface. In order to estimate the switching frequency required for maintaining sufficiently low current ripple with secondorder and fourth-order output filtering, respectively, consider the Fourier series representing of a pulsewidth modulation signal $(\mathrm{D}=0.5)$

$$
\begin{array}{r}
v_{P W M}(t)=\frac{4 V_{S}}{\pi} \sin (2 \pi f t)+\frac{4 V_{S}}{3 \pi} \sin (3 \cdot 2 \pi f t) \\
\frac{4 V_{S}}{5 \pi} \sin (5 \cdot 2 \pi f t)+\ldots
\end{array}
$$

Using fundamental component analysis it can be assumed that

$$
v_{P W M}(t) \approx \frac{4 V_{S}}{\pi} \sin (2 \pi f t)
$$

The transfer function from input voltage to capacitor current for the second-order output filter is

$$
\frac{i_{C}(s)}{v_{P W M}(s)}=\frac{C_{D E A P} s}{C_{D E A P} L_{1} s^{2}+\frac{L}{R} s+1}
$$

If a signal frequency is applied well above $\omega_{0}=\frac{1}{\sqrt{L_{1} C_{D E A P}}}$, equation (4) can be simplified to

$$
\left|\frac{i_{C}(j \omega)}{v_{P W M}(j \omega)}\right| \cong \frac{1}{L_{1} \omega}
$$


The current ripple is found by multipling equation (3) with equation (8)

$$
\Delta i_{C}=\frac{2 V_{S}}{\pi^{2} L f}
$$

For the fourth-order output filter a similar approach can show that

$$
\begin{aligned}
& \frac{i_{C}(s)}{v_{P W M}(s)}=\frac{C_{D E A P S}}{s^{4} L_{1} L_{2} C_{1} C_{D E A P}+s^{3} \frac{L_{1} L_{2} C_{1}}{R}+s^{2}\left(L_{1} C_{D E A P}+L_{1} C_{1}+L_{2} C_{D E A P}\right)+s \frac{L_{1}+L_{2}}{R}+1} \\
& \left|\frac{i_{C}(j \omega)}{v_{P W M}(j \omega)}\right| \cong \frac{1}{L_{1} L_{2} C_{1} \omega^{3}} \\
& \Delta i_{C}=\frac{V_{S}}{2 L_{1} L_{2} C_{2} \pi^{4} f^{3}}
\end{aligned}
$$

Consider a case study where $V_{S}=300 \mathrm{~V}, L_{1}=200 \mu \mathrm{H}$ and $f_{S w}=285 \mathrm{kHz}$, the current ripple through the DEAP transducer becomes $\Delta i_{C}=\frac{2 \cdot 300 \mathrm{~V}}{200 \mu \mathrm{H} 2 \pi 285 \mathrm{kHz}}=1.59 \mathrm{~A}$ peak for the 2th order output filter solution. Assuming $L_{1}=L_{2}=200 \mu \mathrm{H}$ and $C_{1}=100 \mathrm{nF}, \Delta i_{C}=\frac{300 \mathrm{~V}}{2 \cdot 200 \mu \mathrm{H} 200 \mu \mathrm{H} 100 \mathrm{nF} \pi^{4}(285 \mathrm{kHz})^{3}}=16.6 \mathrm{~mA}$ peak for the 4 th order output filter solution. With a worst case series resistance of $10 \Omega$, the 2 th order output filter solution will yield a loss of $8.43 \mathrm{~W}$, while the loss of the 4 th order output filter solution is $0.92 \mathrm{~mW}$. For an amplifier producing a maximum output power of $125 \mathrm{Var}$, the 4th order output filter solution becomes the right choice in terms of efficiency. A formal definition of the efficiency will be given later. Another benefit of the 4th order output filter solution is the possibility for a film capacitor to be used in the first LC-filter stage. The high frequency content will then flow through a capacitor with a frequency response much better than that of the DEAP transducer.

\section{Control}

Hysteresis based self-oscillating control schemes have received great interest in class D audio amplifiers due to the superior loop gain $[11,12,13]$. The switching frequency is defined as

$$
f_{S w}(D)=\frac{D(1-D)}{2 \frac{V_{H y s t}}{K}+t_{D}}
$$

With D been the duty cycle, $t_{D}$ the control-loop delay, $v_{H y s t}$ the height of the hysteresis window, and

$$
K=2 V_{S} \times \operatorname{step}\left\{\lim _{s \rightarrow \infty} G_{C t r l}(s)\right\}
$$

For the purpose of designing the self-oscillation control-loop, the controller transfer function must be defined as

$$
\begin{aligned}
G_{C t r l}(s) & =\frac{v_{\text {Carrier }}(s)}{v_{P W M}(s)} \\
& =K_{V f b_{1}} \frac{v_{C_{1}}(s)}{v_{P W M}(s)}+K_{V f b_{2}} \frac{v_{\text {Out }}(s)}{v_{P W M}(s)}+K_{C f b_{1}} \frac{i_{L_{1}}(s)}{v_{P W M}(s)}+K_{C f b_{2}} \frac{i_{L_{2}}(s)}{v_{P W M}(s)}
\end{aligned}
$$

where definitions from figure $3(\mathrm{a})$ is utilized. 


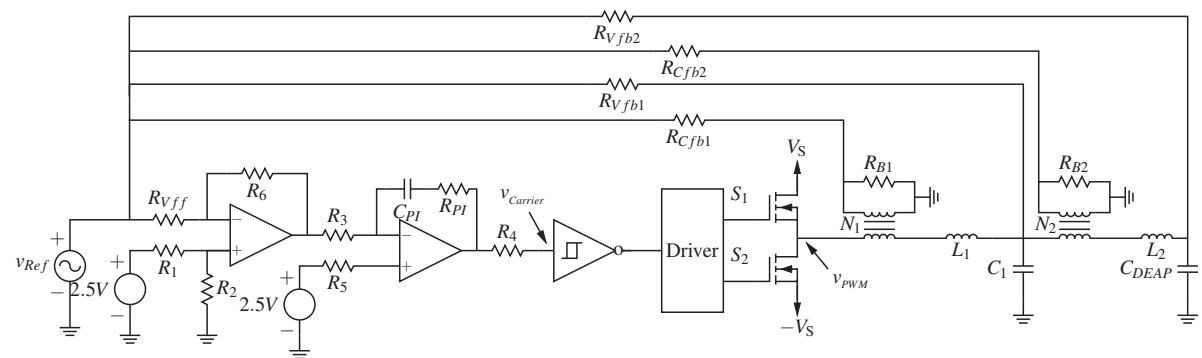

(a) Schematic with single-supply control circuitry.

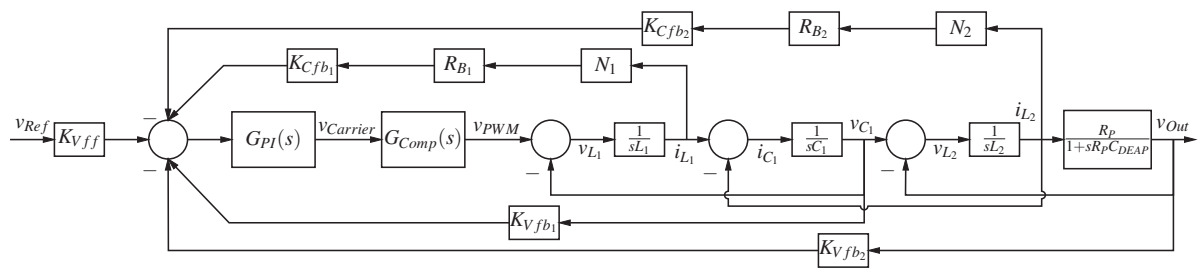

(b) Small-signal model.

Figure 3: Prototype class D amplifier with 4th order output filter and control.

\section{Transfer functions}

The transfer functions of equation (13) are defined as

$$
\begin{aligned}
& \frac{v_{\text {Out }}(s)}{v_{P W M}(s)}=\frac{1}{s^{4} L_{1} L_{2} C_{1} C_{2}+s^{3} \frac{L_{2} L_{1} C_{1}}{R_{P}}+s^{2}\left(C_{1} L_{1}+L_{2} C_{2}+L_{1} C_{2}\right)+s \frac{L 1+L 2}{R_{P}}+1} \\
& \frac{v_{C_{1}}(s)}{v_{P W M}(s)}= \frac{s^{2} L_{2} C_{2}+s \frac{L_{2}}{R_{P}}+1}{s^{4} L_{1} L_{2} C_{1} C_{2}+s^{3} \frac{L_{2} L_{1} C_{1}}{R_{P}}+s^{2}\left(C_{1} L_{1}+L_{2} C_{2}+L_{1} C_{2}\right)+s \frac{L 1+L 2}{R_{P}}+1} \\
& \frac{i_{L_{1}}(s)}{v_{P W M}(s)}=\frac{s^{4} L_{1} L_{2} C_{1} C_{2}+s^{3} \frac{L_{2} L_{1} C_{1}}{R_{P}}+s^{2}\left(C_{1} L_{1}+L_{1} C_{2}\right)+s \frac{L 1}{R_{P}}}{s L_{1}\left(s^{4} L_{1} L_{2} C_{1} C_{2}+s^{3} \frac{L_{2} L_{1} C_{1}}{R_{P}}+s^{2}\left(C_{1} L_{1}+L_{2} C_{2}+L_{1} C_{2}\right)+s \frac{L 1+L 2}{R_{P}}+1\right)} \\
& \frac{i_{L_{2}}(s)}{v_{P W M}(s)}=\frac{s_{2} L_{2} C_{2}+s \frac{L_{2}}{R_{P}}}{s L_{2}\left(s^{4} L_{1} L_{2} C_{1} C_{2}+s^{3} \frac{L_{2} L_{1} C_{1}}{R_{P}}+s^{2}\left(C_{1} L_{1}+L_{2} C_{2}+L_{1} C_{2}\right)+s \frac{L 1+L 2}{R_{P}}+1\right)}
\end{aligned}
$$

The feedback coefficients defined in figure 3(b) are

$$
\begin{aligned}
K_{V f b_{1}} & =\frac{R_{V f b 2}\left\|R_{C f b 1}\right\| R_{C f b 2} \| R_{V f f}}{R_{V f b 2}\left\|R_{C f b 1}\right\| R_{C f b 2} \| R_{V f f}+R_{V f b 1}} \\
K_{V f b_{2}}= & \frac{R_{V f b 2}\left\|R_{C f b 1}\right\| R_{C f b 2} \| R_{V f f}}{R_{V f b 2}\left\|R_{C f b 1}\right\| R_{C f b 2} \| R_{V f f}+R_{V f b 2}} \\
K_{C f b_{1}}= & \frac{R_{V f b 2}\left\|R_{C f b 1}\right\| R_{C f b 2} \| R_{V f f}}{R_{V f b 2}\left\|R_{C f b 1}\right\| R_{C f b 2} \| R_{V f f}+R_{C f b 1}}
\end{aligned}
$$




$$
\begin{aligned}
K_{C f b_{2}} & =\frac{R_{V f b 2}\left\|R_{C f b 1}\right\| R_{C f b 2} \| R_{V f f}}{R_{V f b 2}\left\|R_{C f b 1}\right\| R_{C f b 2} \| R_{V f f}+R_{C f b 2}} \\
K_{V f f} & =\frac{R_{V f b 2}\left\|R_{C f b 1}\right\| R_{C f b 2} \| R_{V f f}}{R_{V f b 2}\left\|R_{C f b 1}\right\| R_{C f b 2} \| R_{V f f}+R_{V f f}}
\end{aligned}
$$

\section{Design}

Using equation (13) and equation (11), the constant $\mathrm{K}$ can be derived

$$
K=\frac{2 V_{s} K_{C f b_{1}} N_{1} R_{B_{1}}}{L_{1}}
$$

It is assumed, that the inner current loop is dominating at the high frequencies.

\section{Experimental results:}

$\mathrm{A} \pm 300 \mathrm{~V}$ half-bridge based class $\mathrm{D}$ amplifier driving a $100 \mathrm{nF}$ load in the midrange region of 0.1-3.5 $\mathrm{kHz}$ is used for experimental verification. The amplifier is build around a Si8235 isolated gate driver and SPA08N80C3 MOSFET's. Figure 4(a) shows a picture of the prototype amplifier. Design parameters are presented in Table I, while derived component values are gathered in Table II.

\section{Efficiency}

When driving a DEAP transducer it is appropriate to give a formal definition of the term efficiency. The first order approximation will yield a capacitive load. Accordingly no real power will be delivered to the load. Efficiency will thus be defined as

$$
\eta=\frac{P_{\text {Out }}}{P_{\text {Out }}+P_{\text {In }}}
$$

where $P_{\text {Out }}=\frac{V_{\text {rms }}^{2}}{\left(\frac{1}{2 \pi f_{\text {Ref }} C_{\text {Deap }}}\right)}$, is the reactive power delivered to the load, and $P_{I n}$ corresponds to the real power consumed by the amplifier. This definition of the term efficiency will be used throughout the paper.

The measured efficiency can be seen in figure 4(b). The efficiency is defined in accordance with equation 24. Note, that the efficiency at $100 \mathrm{~Hz}$ is below $40 \%$. Because the output voltage is kept fixed with respect to frequency, the reactive output power will drop inversely proportional with the frequency. At $100 \mathrm{~Hz}$ the switching loss becomes comparable with the reactive output power. An efficiency above 80 $\%$ is achieved for the frequencies of 1 and $3.5 \mathrm{kHz}$. Voltage mode control of electrostatic transducers is preferred for applications where displacement is of concern. Charge mode control ensures greater linearity at the expense of displacement [14].

\begin{tabular}{lcl}
\hline & Designator & Value \\
\hline Idle switching frequency & $f_{S w}$ & $285 \mathrm{kHz}$ \\
Output filter inductance & $L_{1}$ & $200 \mathrm{uH}$ \\
Output filter inductance & $L_{2}$ & $200 \mathrm{uH}$ \\
Output filter capacitance & $C_{1}$ & $100 \mathrm{nF}$ \\
DEAP Capacitance & $C_{D E A P}$ & $100 \mathrm{nF}$ \\
Supply voltage & $\pm V_{S}$ & $\pm 300 \mathrm{~V}$ \\
Closed loop gain & $A_{V}$ & $75 \frac{V}{V}$ \\
\hline
\end{tabular}

Table I: Design parameters.

\begin{tabular}{lc}
\hline Component & Value \\
\hline$R_{B_{1}}$ & $110 \Omega$ \\
$R_{B_{2}}$ & $10 \Omega$ \\
$C_{P I}$ & $1.5 \mathrm{nF}$ \\
$R_{P I}$ & $1 \mathrm{k} \Omega$ \\
$R_{C b f_{1}}$ & $4 k \Omega$ \\
$R_{C b f_{2}}$ & $4 k \Omega$ \\
$R_{V f f}$ & $2 \mathrm{k} \Omega$ \\
$R_{V f b_{1}}$ & $300 \mathrm{k} \Omega$ \\
$R_{V f b_{2}}$ & $300 \mathrm{k} \Omega$ \\
$R_{1}, R_{2}, R_{3}, R_{4}, R_{5}$ and $R_{6}$ & $1 \mathrm{k} \Omega$ \\
$N_{1}$ and $N_{2}$ & $\sqrt{\frac{200 \mathrm{nH}}{980 u H}} \approx 0.014$ \\
\hline
\end{tabular}

Table II: Component values. 


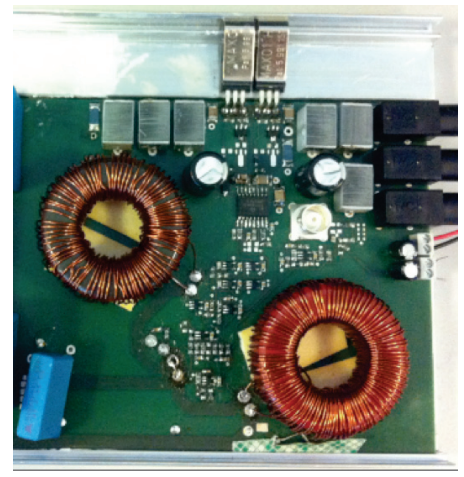

(a) Picture of prototype amplifier.

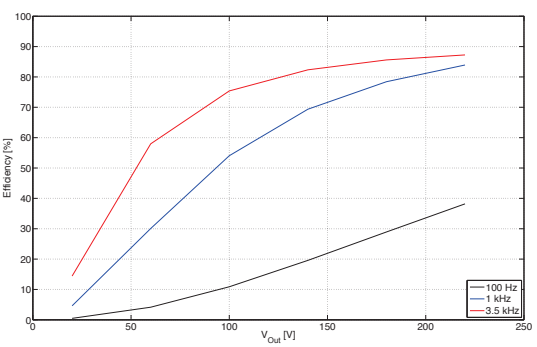

(b) Efficiency.

Figure 4: Prototype amplifier.

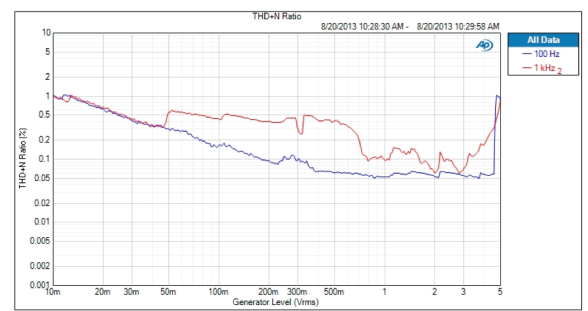

Figure 5: THD+N of the prototype for reference frequencies of $100 \mathrm{~Hz}$ and $1 \mathrm{kHz}$.

\section{THD+N}

THD $+\mathrm{N}$ is measured using an APX525 audio analyzer and a voltage attenuation interface. The voltage attenuation interface is necessary in order to protect the input-stage of the audio analyzer. Design and implementation of the voltage attenuation interface is well-described in the literature [10, 15]. Figure 5 gives the measured THD $+\mathrm{N}$ as a function of the reference voltage for the frequencies of $100 \mathrm{~Hz}$ and 1 $\mathrm{kHz}$. THD+N is below $0.1 \%$ over a significant part of the operation range for the reference frequency of $100 \mathrm{~Hz}$. Noise is the dominating factor in the measured THD+N.

\section{Conclusion:}

A class D audio amplifier with 4th order output filter for capacitive transducers is proposed and analyzed. The amplifier addresses the issues of high series resistance and limited frequency response of the capacitive transducers, potentially paving the way for increased industry adoption of this highly promising technology. THD+N below $0.1 \%$ is reported for the $\pm 300 \mathrm{~V}$ prototype amplifier producing a maximum of 125 Var at a peak efficiency of $87 \%$.

\section{References}

[1] K. Nielsen, "Audio power amplifier techniques with energy efficient power conversion," Ph.D. dissertation, Technical University of Denmark, 1998.

[2] S. Poulsen, "Towards active transducers," Ph.D. dissertation, Technical University of Denmark, July 2004.

[3] S. Poulsen and M. A. E. Andersen, "Hysteresis controller with constant switching frequency," Consumer Electronics, IEEE Transactions on, vol. 51, no. 2, pp. 688-693, 2005.

[4] S. Poulsen and M. A. E. Andersen, "Simple pwm modulator topology with excellent dynamic behavior," in Applied Power Electronics Conference and Exposition, 2004. APEC'04. Nineteenth Annual IEEE, vol. 1. IEEE, 2004, pp. 486-492. 
[5] S. Poulsen and M. A. Andersen, "Practical considerations for integrating switch mode audio amplifiers and loudspeakers for a higher power efficiency," in Audio Engineering Society Convention 116, 2004.

[6] R. Sarban, R. Jones, B. Mace, and E. Rustighi, "A tubular dielectric elastomer actuator: Fabrication, characterization and active vibration isolation," Mechanical Systems and Signal Processing, vol. 25, no. 8, pp. 2879-2891, 2011.

[7] R. Heydt, R. Kornbluh, R. Pelrine, and V. Mason, "Design and performance of an electrostrictivepolymer-film acoustic actuator,' Journal of Sound and Vibration, vol. 215, no. 2, pp. 297-311, Aug. 1998.

[8] R. Heydt, R. Pelrine, J. Joseph, J. Eckerle, and R. Kornbluh, "Acoustical performance of an electrostrictive polymer film loudspeaker," Journal of the Acoustical Society of America, vol. 107, no. 2, pp. 833-839, Feb. 2000.

[9] D. Nielsen, A. Knott, and M. A. E. Andersen, "Hysteretic self-oscillating bandpass current mode control for class d audio amplifiers driving capacitive transducers," 2013.

[10] D. Nielsen, A. Knott, and M. A. E. Andersen, "Driving capacitive transducers," in Audio Engineering Society, 134th Convention, Ed. Rome, Italy, 2013.

[11] M. C. Høyerby and M. A. Andersen, "Derivation and analysis of a low-cost, high-performance analogue bpcm control scheme for class-d audio power amplifiers," in Audio Engineering Society Conference: 27th International Conference: Efficient Audio Power Amplification, 2005.

[12] M. C. W. Hoyerby and M. A. E. Andersen, "Carrier distortion in hysteretic self-oscillating class$\mathrm{d}$ audio power amplifiers: Analysis and optimization," IEEE Transactions On Power Electronics, vol. 24, no. 3-4, pp. 714-729, Mar-Apr 2009.

[13] M. Høyerby and M. Andersen, "A small-signal model of the hysteretic comparator in linear-carrier self-oscillating switch-mode controllers," Norpie, 2006.

[14] J. Borwick, Loudspeaker and Headphone Handbook, third edition ed. Reed Educational and Professional Publishing Ltd, 2001, no. 0240515781.

[15] A. P. Inc., "Measuring high impedance sources," http://ap.com/kb/show/314, 2010. 